\title{
Pollen Morphology of Some Members of Nigerian Clusiaceae and Its Taxonomic Significance
}

\author{
${ }^{1}$ Nnamani, C. V., ${ }^{2}$ Nwosu, M. O. \\ ${ }^{1}$ United Nations University Institute of Natural Resources in Africa/ Ebonyi State University Abakaliki, Nigeria \\ ${ }^{2}$ Department of Botany, University of Nigeria, Nsukka, Nigeria
}

\begin{abstract}
The palynological features of three members of Nigerian Clusiaceae were assessed by light microscopy $(L M)$ after acetolysis in order to determine the observed external and internal peculiarities of these species, with respect to their taxonomic implications. These species were Harungana madagascariensis (Lam.) ex Poir., Garcinia kola Heckel. and Pentadesma butyracea Sabine. Results revealed many interesting palynological features with significant taxonomic values. Pollen grains are radially symmetrical, shed in monads and isopolar in all the taxa. Apertural types are tetracolporate and zonocolporate for G. kola and P. butyracea but tricolporate in $\mathrm{H}$. madagascariensis. Pollen form indices vary significantly from $0.55 \pm 0.02,1.59$ \pm 0.12 and $1.18 \pm 0.01$ to give pollen shapes of oblate spheroidal, spheroidal and subspheroidal for $H$. madagascariensis, G. kola and P. butyracea, respectively. Pore orientation is angulaperturate in all while the exine ornamentations were coarsely psilate in G. kola and P. butyracea but reticulate in $\mathrm{H}$. madagascariensis. The above features are of high taxonomic value in the classification of these species. Their taxonomic implications were discussed.

Key Words: Taxonomic Values, Pollen Features, Nigerian, Cluusiaceae,
\end{abstract}

\section{Introduction}

The Clusiaceae include herbs, shrubs and trees with sap resinous and abundant oil glands. Leaves are opposite or whorled, rarely alternate and exstipulate while flowers are usually unisexual, sometimes bisexual on the same plant (Keay 1954, Lawrence, 1968) and functionally polygamodioecious, actinomorphic with sepals 210 or more. Petals range from 4-12, usually imbricate, subvalvate or contorted. Stamens are few or numerous, hypogenous, distinct and variously united. Anther is 2-celled and dehiscing longitudinally. Pistil is 1 , ovary superior, 1 to many loculed; carpels are usually 3 to 5 or as many as the locule (Robson, 1961, Matig et al., 2007).

This family is very important economically, with some members having very high socio-economic, industrial, ethno medicinal and pharmacological values.

The Igbo and Efik cultures in Southeastern Nigeria use $H$. madagascariensis medicinally for the treatment of ulcer and asthma (Inyang, 2003). Leaves are mixed with water, made into a paste and applied topically to treat ringworm, conjunctivitis, rashes and fevers (Madubunyi, 1995). Fresh leaf juice is applied topically to treat abscesses, while young leaves are boiled in water and the resulting "tea" is administered orally three times a day as an analgesic and for whooping cough. In addition, dried leaf infusion is administered orally in Nigeria to treat stomach problems, leprosy and it equally serves as an oxytocic and abortifacient (Bisby et al., 2007).

Economically, a mature tree of G. kola can yield about 500 fruits, providing 1700 nuts per year, with an average of N50- 60,000.00 proceed annually. It serves as a very good source of income for women and men in Igbo land (Okafor, 2001, Adebisi, 2002, Okeke, personal opinion, 2010,). The seeds are widely eaten in Igbo land as masticant.

G. kola is used in natural dental care to prevent dental caries (Eyogi et al., 2007). The bark is used for tanning while in the last 3- 4 years, the seeds have also been used as an industrial bittering agent in some Nigerian breweries (Aniche and Uwakwe, 2010). the fruit pulp is used for the treatment of jaundice or high fever (Esimone et al., 2002).The nuts are dried, ground and mixed with honey to make a traditional cough mixture (Adebisi, 2002).

In Southern Nigeria a cold water extract of root-bark with salt is administered to ease off bronchial asthma or cough and vomiting (Farombi et al., 2005), while the fruits are eaten in Nigeria as a cure for general aches in the head, back and as well as a vermifuge. Igbo medicine-men prescribe the fruit for arthritic conditions while the latex from the stem is applied externally to treat parasitic skin diseases and for tropical sores (Liu et al., 2005).

In line with the above remedies ASICUMPON (2005) opined that the seed is an aphrodisiac and that palm wine tapers use it when tapping to scar away snakes. They concluded that, it also serves as antidote to poison while the leaves that have bitter taste are used as purgative. 
Aduradola (1999) opined that the biflavonoid compound found in G. kola has anti-inflammatory, antimicrobial, anti- diabetic and antiviral properties. He further stated that the extract from seeds have been formulated into various dosage forms including tablets, lozenges, creams, vials and toothpaste.

A recent study reported a reduction in subchondral pressure and pain in knee osteoarthritis due to $G$. kola intake (Adegbehingbe et al., 2008) it has also proven to be safe in human eyes and its systemic blood pressure lowering effects has been published in previous studies (Adefule et al., 2004).

The fat acid composition from $P$. butyracea seed has been analyzed for its chemical and physical constancy and when compared with those of the known cocoa butter and shea butter; it was discovered to contain 50.0, 52.1, and 53.4\% of fat, respectively. Their fats are similar in many of their characteristics, particularly in their slip point, saponification number and solidification point. Butter tree fat has a much lower unsaponification matter content of $1.5-1.8 \%$ than Shea butter that has 7.3- 9.0\%. They further stated that the profile aesthetically gives the butter a distinct texture and their replacement fats in respect to their melting points are quit unique (Tchobo et al., 2007).

However, the inclusion of $H$. madagascariensis in the Clusiaceae has been a source of confusion to both botanist and other researchers, this because it shears many morphological features with members of this family. It therefore becomes imperative to carry out palynological assessment of some members of these taxa to aid their proper classification. The main objectives of this work were to 1) assess the palynological feature of these species, 2) determine external and internal peculiarities of these features and 3) evaluate their taxonomic values.

\section{Sample collection}

\section{Materials and Methods}

Specimens were collected from their natural habitats in the various study sites in Southern and Southeastern parts of Nigeria, Enugu State Forest Reserve, Enugu, Odenigbo in Nsukka Local Government Area of Enugu State, Adada Forest along Adada River at Nkpologu, Uzo Uwani Local Government Area of Enugu State. Others were from Staff farm in the Faculty of Biological Sciences, Ebonyi State University, Abakaliki, Forestry Research Institute of Nigeria (FRIN) at Benin in Edo State and Forestry Research Institute of Nigeria (FRIN) at Ikom in Cross River State.

Specimens were identified with the aid of Keay, 1954; Benson, 1957; Keay, 1989). Voucher specimens of these plants are deposited in the Herbaria of the Department of Botany, University of Nigeria, Nsukka (UNH) and Department of Applied Biology, Ebonyi State University, Abakaliki, Nigeria.

\section{Preparation of sample}

Fresh polleniferous buds from H. madagascariensis, G. kola and P. butyracea were obtained from the field. Mature buds which had not undergone anthesis were removed from these shoots. Anthers were teased off from the flower buds into five $\mathrm{ml}$ of $70 \%$ alcohol in $25 \mathrm{ml}$ beakers. They were squashed with a glass rod. This process breaks the anthers to release the pollen grains. The solutions were sieved with fine network mesh of wire gauze (sterilized under the Bunsen burner to avoid contaminations). This process removes all the plant tissues.

The solutions were then centrifuged at 2000 revaluation per a minute (R P M) for 5 minutes. They were washed twice with distilled water, centrifuged and then decanted again. Acetolysis

The precipitates were acetolyzed according to a modified version of Erdtman's (1971) acetolysis method of 9:1 conc. sulphuric acid and acetic anhydride for ten minutes. They were centrifuged, decanted and wished twice with distilled water. The recovered precipitates were stored in vials with ten drops of glycerin, for subsequent light microscopy.

Temporary slides were prepared, pollen grains were mounted in glycerin jelly and examined using light Olympus CH Trinocular microscope (LM) fitted 650 IS Cannon Digital Camera at x 400 and x 100 magnifications.

The following parameters were assessed qualitatively and quantitatively: polar diameter, equatorial diameter, pollen form index, exine thickness, shape in polar view, shape in equatorial view, sculpturing type, aperture type, dimension of pore at polar and equatorial views. Terminology for pollen descriptions were adopted from Erdtman (1971), and Punt et al., (1994). All measurements and photomicrographs were taken under x 1000 magnification.

Analyses for palynological data were based on 20 measurements for a feature per slide for the four slides per a sample. These values were tabulated with the species description citing Mean Standard Errors only for some of the important pollen features. 


\section{Polarity and Symmetry of pollen grains}

\section{Results}

Pollen grains are radially symmetrical, isopolar, generally shed in monads and rarely in tetrads.

Shapes

Pollen shapes are oblate- spheroidal; amb in polar view is triangular, concave with an oblate outline in equatorial view for $H$. madagascariensis while it was spheriodal equatorially, amb in polar view is circular in outline for G. kola and subspheriodal with circular outline in polar view for P. butyracea.

The pollen form indices were $0.55 \pm 0.02 \mu \mathrm{m}, 1.59 \pm 0.12$ and $1.18 \pm 0.01$ for $H$. madagascariensis, $G$. kola and $P$. butyrace, respectively, while polar and equatorial axis $116.65 \pm 0.10,859.04 \pm 0.65,868.8 \pm 1.30$, $211.19 \pm 0.25,539.94 \pm 0.75$ and $737.14 \pm 0.70$, respectively (Table 1 ).

\section{Aperture}

Pollen grains are tricolporate, zonocolporate and non lophate while pore orientation was angulaperturate (Table 2) with pore length and breadth of $121.09 \pm 0.10$ and $12.22 \pm 0.01$, respectively for $H$. madagascariensis; and apoporium was $34.44 \pm 01 \mu \mathrm{m}$ while mesocolpium is $23.31 \pm 0.01 \mu \mathrm{m}$. In G. kola pollen grains are tetracolporate, zonocolporate, and non lophate (Table 2). Pore orientation was angulaperturate with apertural length and breadth of $424.4 \pm 0.30$ and14.44 \pm 0.25 (Table 2). Apocolpium is $292.19 \pm 0.50 \mu \mathrm{m}$ while mesocolpium is $199.98 \pm 0.1 \mu \mathrm{m}$, respectively (Fig. 2). P. butyracea grains are tetracolporate, zonocolporate and non lophate (Table 2). Apertural length and breadth are $836.58 \pm 0.5$ and $83.33 \pm 0.35$, respectively, while pore orientation is angulaperturate. Pore diameter at equatorial view is $24.18 \pm 0.45$ while apocolpium is $264.42 \pm$ $0.83 \mu \mathrm{m}$ and mesocolpium of $384.41 \pm 0.13 \mu \mathrm{m}$, respectively (Fig. 2).

\section{The Exine}

Pollen ornamentation is reticulate, tectate, without carvae and a thickness of $22.22 \pm 0.05 \mu \mathrm{m}$ (Table 2 and Fig. 3) while pollen ornamentation is psilate G. kola, tectate with an exine thickness of $43.33 \pm 0.10 \mu \mathrm{m}$, a thick margo and a carvae of about $0.42 \pm 0.10$. Apoporium and mesocolpium are about $292.19 \pm 0.50$ and $199.98 \pm 0.1$, respectively (Figure 2).

In $P$. butyracea pollen ornamentation is psilate, tectate with an exine thickness of $83.32 \pm 0.46 \mu \mathrm{m}$. (Figures 2 , 3 , and Table 1). There is the presence of a thick carvae of about $0.22 \pm 0.05 \mu \mathrm{m}$ with apocolpium and mesocolpium of $264.42 \pm 0.83$ and $384.41 \pm 0.13$, respectively (Table 1 and Figure 2).

Table 1: Quantitative Data on Pollen Features of the Three Clusiaceae Species (mean standard error in $\boldsymbol{\mu m}, \mathbf{x}$ 1000).

\begin{tabular}{lccc}
\hline \multicolumn{1}{c}{ Pollen Character } & H. madagascariensis & G. kola. & P. butyracea \\
\hline Polar diameter & $116.65 \pm 0.10$ & $859.04 \pm 0.65$ & $868.8 \pm 1.30$ \\
Equatorial diameter & $211.19 \pm 0.25$ & $539.94 \pm 0.75$ & $737.14 \pm 0.70$ \\
Exine Thickness & $18.22 \pm 0.05$ & $43.33 \pm 0.10$ & $83.32 \pm 0.50$ \\
P D E V & $0.22 \pm 0.05$ & $14.44 \pm 0.05$ & $24.18 \pm 0.45$ \\
Pollen Form Index & $0.55 \pm 0.02$ & $1.59 \pm 0.12$ & $1.18 \pm 0.01$ \\
Carvae & - & $0.42 \pm 0.10$ & $0.22 \pm 0.05$ \\
\hline
\end{tabular}

P D E V-pore diameter at equatorial view

Table 2: Apertural and Sculptural Features of the Three Species

\begin{tabular}{llllll}
\hline Species & APT & NAP & SCPT & SPPV & SPEV \\
\hline H. madagascariensis & Tricolporate & 3 & Reticulate & Angular & Oblate Spheroidal \\
G. kola. & Tetracolporate & 4 & Psilate & Circular & Spheriodal \\
P. butyracea & Tetracolporate & 4 & Psilate & Circular & Subspheroidal \\
\hline
\end{tabular}

Legend :A PT- Apertural type, NAP- No of apertures, SCPT- Sculpturing type, SPPV-Shape of pollen at polar view, SPEV-Shape of pollen at equatorial view 


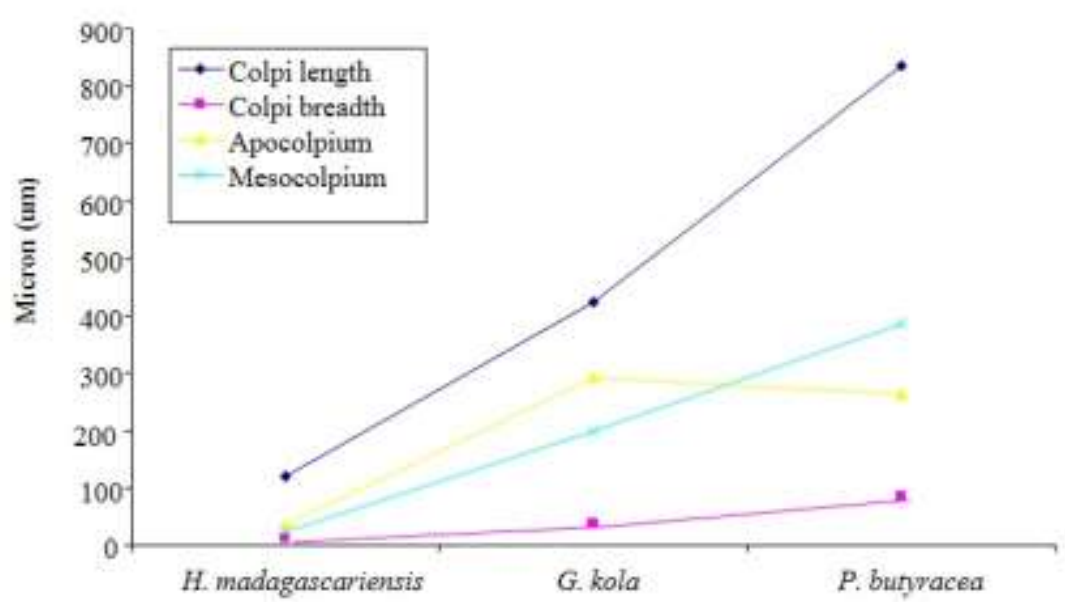

Figure 2: Pollen and Apertural Features for the Four Species

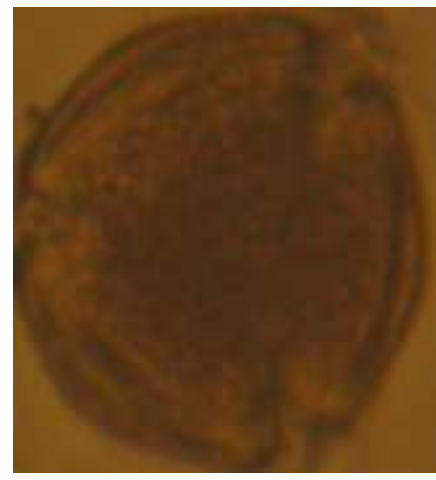

1

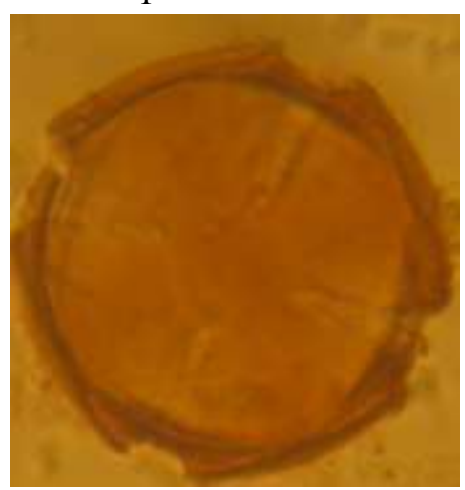

4

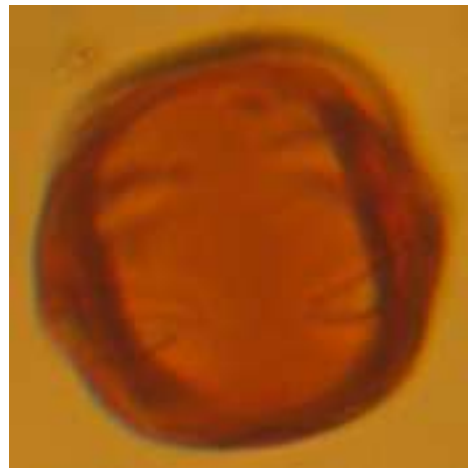

7

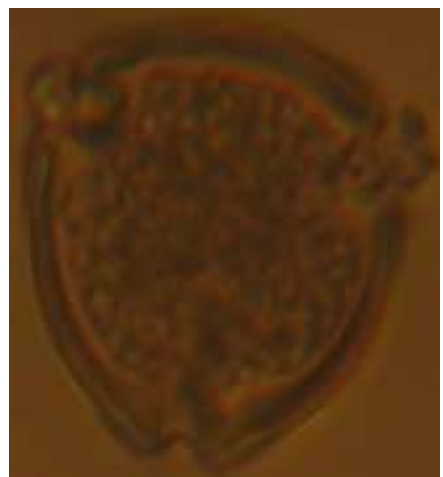

2

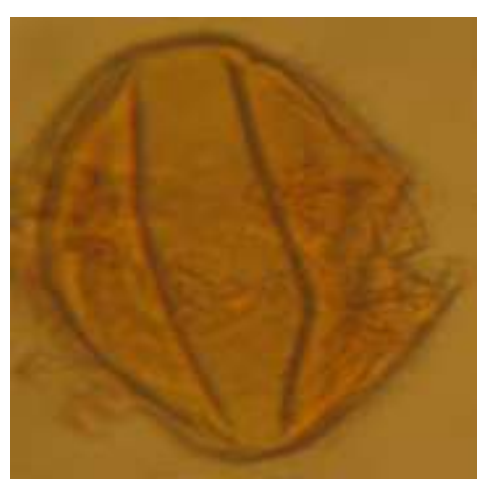

5

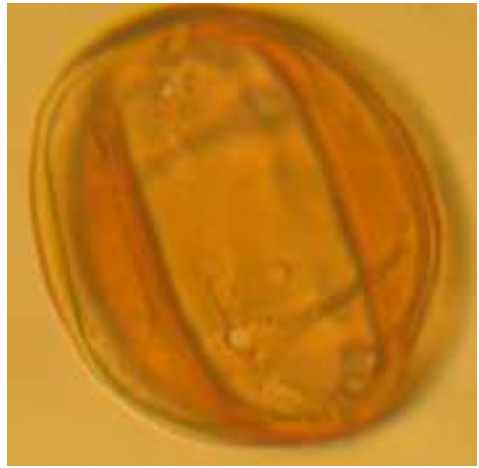

8
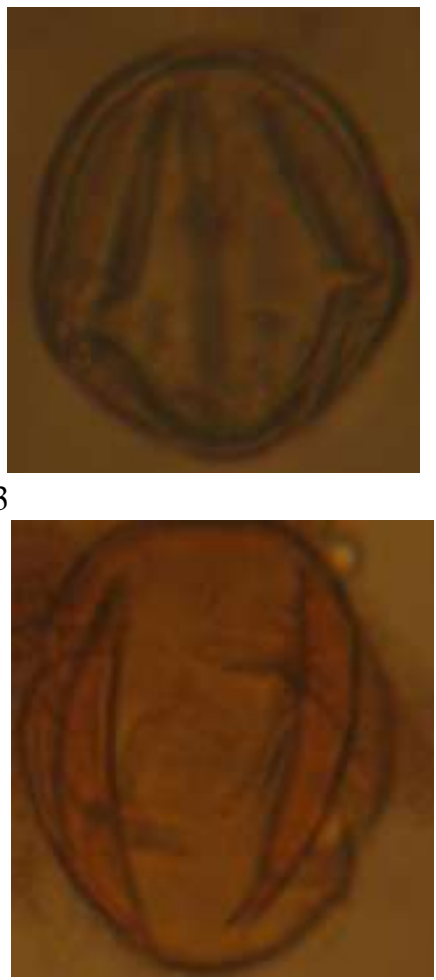

6

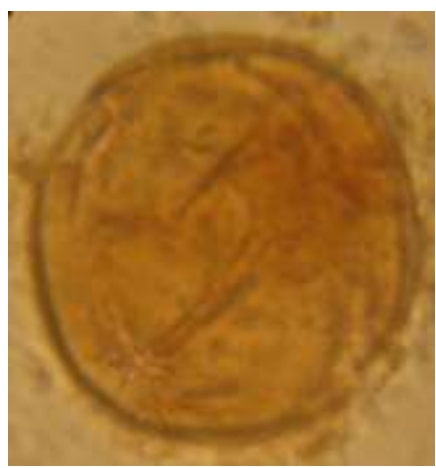

9

Figure 3: Pollen Features of the Nigerian Clusiaceae- 1-3 H. madagascariensis. 4-6.G. kola and 7-9. P. butyracea 


\section{Discussion}

This palynological study sought to provide more useful information on the taxonomy of these taxa. The three species assessed show interesting features with significant taxonomic values. These variations actually reinforce the morphological and anatomical data obtained from earlier work.

\section{Apertural and Sculpturing type}

This study recorded two apertural types, the tetracolporate type with psilate sculpturing ornamentation in both G. kola and P. butyracea with tricolporate and reticulate type found in H. madagascariensis (Figures 3 and Table 2). The above results were in line with the findings of Passarelli et al., (2010) who in their work reported of psilate ornermentation in Podostemum spp in the family Podostemumaceae, a basal sister group of the Clusiaceae. This is equally in conformity with the report of Furness et al., (2004) ; Perveen and Qaiser, (2007) who reported that pollen grains do not differ within most families and as such can be of great value in establishing affinity or otherwise.

These distinctive pollen apertural and sculpturing types could be used in the taxonomic delimitation of $H$. madagascariensis from the rest of the genera. It equally affirms the excluded taxonomic status of $H$. madagascariensis, as well as the close affinity of G. kola and P. butyracea.

The absence of reticulate ornamentation pattern in G. kola and P. butyracea (except in the $H$. madagascariensis) is in accordance with the observations of Punt et al., (1994), who found coarsely psilate sculpturing pattern with distinctively large pollen in the exotic species of this Clusiaceae. This result is in agreement with the reports of Bashir and Khan (2003), Mbagwu and Edeoga (2006) and Mbagwu et al., (2009) who in their various works utilized apertural attributes of pollen grains to establish probable evidence of relationships among some species in many genera of flowering plants. They suggested that pollen morphology can be useful in supporting taxonomic evidence and could be used in solving taxonomic controversies in the classification of problematic taxa.

Dessein et al., (2005) however, noted that the number of apertures are positively correlated with pollen size, since the larger the pollen grain, the larger the surface area where the colpi may be initiated. They stressed that more colpi may facilitate higher germination. They further, reported that a possible explanation may be found in the harmomegathy function of the colpi, a process by which the pollen and spores change in shape, to accommodate variations in the volume of the cytoplasm caused by the changes in dehydration.

However, the present observations conform totally with this report by Dessein et al., (2005), because all the examined taxa except $H$. madagascariensis are large with larger number of colpi but on the other hand, they do not germinate easily from all the available literature.

\section{Shape of pollen}

Pollen shapes in polar view are angular in H. madagascariensis, circular in G. kola and P. butyracea while the equatorial shapes were oblate spheroidal, spheriodal and subspheroidal in $H$. madagascariensis, $G$. $k o l a$ and $P$. butyracea, respectively. The above variations could be attributed to their intergeneric differences.

However, Lowe and Soladoye (1990) and Ogwal (1990) suggested that, it is likely that the nature or shape of pollen grains could be an evolutionary modification often inherited to determine the mode of pollination and thereby perpetuate a particular group of plant in a given environment.

In the same line, Mbagwu and Edeoga (2006), were of the opinion that, where the pollen grain is longer than wide, it may be explained as a structural adaptation for effective dispersal by wind while the circular nature of some of the pollen grains were related to structural adaptation for effective pollination by insects. The above opinions if right may not apply to the above shapes found in all these species. This inference is deduced because based on the floral morphology of these species, they are all entomophilous plants.

\section{Size, Symmetry and Dispersal Unit}

Pollen size of these species varied considerably within the taxa. These variations between polar and equatorial diameter gave an explanation to the oblate spheriodal, spheriodal and subspheroidal shapes found in H. madagascariensis, G. kola and P. butyracea, respectively. The pollen grains are shed in monads in all the species; they are radially symmetrical and isopolar. The above features are not taxonomically informative, but rather show evidence of their levels of advancement.

\section{Exine Thickness}

The exine of these species varies significantly in H. madagascariensis, G. kola and P. butyracea. $H$. madagascariensis had the smallest exine thickness while $G$. kola had the thickest exine walls. $H$. madagascariensis with its thin exine wall is considered more primitive than $G$. kola and P. butyracea which are more advanced by possessing pollen grains with thicker exine walls. This is in line with the report of Tomsovie (1997) and Sahreen et al., (2008) who observed that the presence of thin exine with reduced columellae is a characteristic feature of primitiveness in Angiosperms. 


\section{References}

[1] Adebisi, A. A. (2002). A Case Study of Garcinia kola Nut Production to Consumption System in J4. Area of Omo Forest Reserve. In: Sunderland, T. and Ndoye, O. (eds). Forest Products, Livelihood and Conservation. Africa Publishers. 139 p p.

[2] Adebukunola, O., Adefule-Ositelu, B. O., Adegbehingbe, A. K. Adefule, O. O., Adegbehingbe, E. S. and Kehinde O. (2010) Efficacy of Garcinia kola $0.5 \%$ aqueous eye drops in patients with primary open-angle glaucoma or ocular hypertension. East African Journal of Ophthalmology. 17:1,88-93.

[3] Adefule, A. K., Oosa, B. O. and Onyenafa, P. C. (2004). Antifungal Activities of Garcinia kola Extracts on Purulent Discharges in Lagos University Teaching Hospital, Lagos, Nigeria. Quarterly Journal Hospital Medicine. 14: 112-114.

[4] Adegbehingbe, O. O, Adesanya, S. A, Idowu, T. O, Okimi, O. C, Oyelami, O. A, Iwalewa, E. O. (2008). Clinical Effects of Garcinia kola in Knee Osteoarthritis. Journal of Orthop Surgone; 3:34-38.

[5] Aduradola, A. M. (1999). Preliminary Investigation of some Factors Affecting of Tropical Ethnoforestry 2(1): 47-46.

[6] Aniche, G. N. and Uwakwe, G. U.( 2010). Potential Use of G. kola as Hop Substitude in Large Beer Brewing. World Journal of Microbiology and Biotechnology: 6: 3, 87-82.

[7] ASICUMPON, (2005). Check List of Medicinal Plants of Nigeria and their Uses. Trinity Biz Publishers, Nigeria, 135, pp.

[8] Bashir, S. and Khan, M. A. (2003). Pollen Morphology as an Aid to the Identification of Medicinal Plants: Trianthema portulacastrum L., Boerhaavia procumbens Banks ex Roxb. and Alternanthera pungens Kunth. J. Hamdard Medicus, XLVI: 7-10.

[9] Bisby, F. A., Roskov, Y. R., Ruggiero, M. A., Orrell, T. M., Paglinawan, L. E.; Brewer, P. W. and Bailly, N. (2007). Species 2000 and ITIS Catalogue of Life: In: Hertum, J. V. (ed) 2007 Annual Checklist. Reading, U.K.

[10] Bonsen, K.. J. M. and Kucera, L. J. (1990). Vessel Occlusion in Plants: Morphological and evolutionary Aspects. International Association of Wood Anatomists Bulletin II (4): 393-399.

[11] Burkhill, H. M. (1994). The Useful Plants of West Tropical Africa. Vol. 4. Royal Botanic Gardens Kew. 969, pp.

[12] Dessein, S., Harwood, R., Smmets, E. and Robbrecht, E. (2005). Pollen of the Spermacoce (Rubiaceae) Species from the Northern Territory of Australian: Morphology and Taxonomic Significance. Australia Systematic Botany, 18: 367-382.

[13] Erdtman, G. (1971). Pollen Morphology and Plant Taxonomy (Angiosperm). Hafner Publishing Company, New York.

[14] Esimone, C. O., Nwafor, S. O .V., Okoli, C. O., Chah, K. F., Uzuegbu, D. B., Chibundu, C. and Adikwu, M. U. (2002). In Vivo Evaluation of Interaction between Aqueous Seed Extract of Garcinia kola and Ciprofloxacin Hydrochloride. American Journal of Therapeutics. 9 (4): 275-280.

[15] Eyogi, O. M., Aoudji, A. K. and Linsoussi, C. (2007). Garcinia kola Seed Dormancy Breaking. Applied Ecology and Environmental Research. 5 (1): 63-71

[16] Farombi, E. O., Akanni, O. O. and Emerole, G. O. (2005). Antioxidant and Scavenging Activities of Flavonoid Extract (Kolaviron) of Garcinia kola Seeds in Vitro. Pharmacological Biology. 40 (2) 1: 107-116.

[17] Furness, C. A. and Rudall, P. J. (2004). Pollen Apertural Evolution: A Crucial Factor for Eudicot Success? Trends in Plant Science 9:1360-1385.

[18] Inyang, E. (2003). Ethnobotany, Conventional and Traditional Uses of Plants. Verdict Press, Nigeria.,191, pp.

[19] Liu, Y., Qiu, Y. P., Hang, L. Z. and Chen, 1. (2005). Dormancy Breaking and Storage Behaviour of Garcinia kola Seeds: Implications for Ecological Functions and Germplasm Conservation. Journal of Integrated Biology. 471(1): 38-49.

[20] Lowe, J. and Soladoye, M. O. (1990). Some Changes and Corrections to Names of Nigerian Plants and Nigerian Trees since the Publication of Flora of West Tropical Africa. 2nd Ed. Nigerian Journal of Botany, 3:1-24.

[21] Madubuuyi, I. I. (1995). Antimicrobial Activities of the Constutient of G. kola Seeds Int Journal of Pharmacognocy 33: 232-237.

[22] Matig, A. L., Aoudji, A. K. N. and Linsoussi, A. (2007). G. kola Seed Dormancy- Breaking Applied Ecology and Environmental Research 5(1): 63-71.

[23] Mbagwu, F. N. and Edeoga, H. O. (2006). Palynological Studies on Some Nigerian Species of Vigna spp. Journal Biological Science 6 (6): 1122-1125

[24] Mbagwu, F. N., Chime, E. G. and Unamba, C. I. N. (2009). Palynological Studies on Five Species of Asteraceae. African Journal of Biotechnology Vol. 8 (7), 1222-1225.

[25] Metcalfe, C. R. and Chalk, L. (1957). Anatomy of the Dicotyledons, Vol 1, Oxford University Clarendon Press, London. 726 pp.

[26] (1965). Anatomy of the Dicotyledons. Vol. 2. Clarendon Press, Oxford, London. pp. 726-1460.

[27] Nasreen, S., Yousa, F. M., Mohmand, A. S. and Ashraf, M. (2002). Study of Seed Dormancy

[28] Nnamani, C. V. and Agwu, C. O. C. (2007). Pollen Analysis of Honey Samples from Ebonyi State Nigeria. Bio-Research: 5 (1) 184-188.

[29] (2008). Index of Phytoecological Indicator Species in Five Honey Samples from Ebonyi State Nigeria. Nigerian Journal of Botany $21(1): 129-135$

[30] Nzegbule, E. and Mbakwe, R. (2001). Effect of Pre-Sowing and Incubation Treatment on Germination of Garcinia kola Seed. Fruits, 56: 437-442.

[31] Okafor, J. C. (2001). Case Study: Role of Conservation and Domestication of Minor Woody Forest Plants for Local Communities in Nigeria. In: F. T Last (ed) Ecosystesm of the World (19), Tree Crop Ecosystem, Elevier, Amsterdam-London, pp.7-17.

[32] Ogwal, E. N. K. (1990). A Taxonomic Investigation of the Genus Commelina in Uganda. Proceedings AETFAT. Hamburg, 236: $573-592$.

[33] Perveen, A. and M. Qaiser, (2007). Pollen Floral of Pakistan - Malvaceae - Grewioideae - LII. Pakistan Journal of Botany. 39 (1): $1-7$

[34] Passarelli, L. M., Tur, N. M. and Girarde, S. B. (2010). Morphology of Pollen of the Species of Neo-Tropical of Pododstemum (Podostemaceae). International Journal of Tropical Biology and Conservation:58 (1), 82-88.

[35] Punt. W. W.W., Nilsson, S., Blackmore, S. and Thomas, L. A. (1994). Glossary of Pollen and Spore Terminology, -L P P Foundation, Utrecht, L P P Contribution Series No, 1

[36] Sahreen, S., Khan, M. A., Meo, A. A. and Jabeen, A. (2008). Pollen Morphology of the Genus Silene (Sileneae-Caryophyllaceae) from Pakistan. Biological Diversity and Conservation 1 (2): 74-85.

[37] Tchobo, F. P., Natta, A. K, Barea, B., Barouh, N., Piombo, G. P. M, Villeneuve, P., Soumanou, M. M. and Sohounhloue,D. C. K. (2007). Characterization of Pentadesma butyracea Sabine Butters of Different Production Regions in Benin. Journal of the American Oil Chemists' Society 84 (8) 755-780.

[38] Tomsovic, P. (1997). Some Palynological Observations on the Genus Echinops (Asteraceae) and their Taxonomic Implications. Preslia, Praha, 69: 31-33.

[39] Zafar, M., Khan, M. A., Ahmad, M. and Sultana, S. (2006). Palynological and Taxonomic Studies of Some Weeds from Flora of Rawalpindi, Pakistan Journal of Weed Science Research. 12 (1-2): 99-109. 